07,14

\title{
Изменение структуры и механических свойств жесткоэластических и пористых пленок полипропилена при отжиге и ориентации
}

\author{
() Г.К. Ельяшевич ${ }^{1}$, И.С. Курындин ${ }^{1}$, В.К. Лаврентьев ${ }^{1}$, Е.Н. Попова ${ }^{1}$, V. Bukošek ${ }^{2}$ \\ ${ }^{1}$ Институт высокомолекулярных соединений РАН, \\ Санкт-Петербург, Россия \\ ${ }^{2}$ University of Ljubljana, Faculty for Natural Sciences and Engineering, \\ Ljubljana, Slovenia \\ E-mail: elya@hq.macro.ru
}

(Поступила в Редакцию 10 апреля 2018 г.)

\begin{abstract}
Исследовано влияние температуры отжига на характеристики жесткоэластических образцов полипропилена, полученных отжигом экструдированных пленок и имеющих ориентированную ламеллярную структуру. Методами рентгеновского рассеяния и дифференциальной сканирующей калориметрии установлено, что с повышением температуры отжига увеличивается толщина ламелей, большой период и степень ориентации складчатых ламелей, что сопровождается ростом температуры и энтальпии плавления. Пористые пленки получены одноосным растяжением отожженных образцов в направлении ориентации. Показано, что при повышении температуры отжига возрастает пористость и проницаемость пористых пленок в результате увеличения числа и размеров сквозных каналов. Измерены механические характеристики (прочность, модуль упругости и удлинение при разрыве) жесткоэластических и пористых пленок и установлена их связь с изменениями структуры и ориентации образцов в зависимости от температуры отжига.
\end{abstract}

Работа проведена при поддержке Проекта совместных исследований РАН и Университета Любляны (Словения) ARRS-BI-RU/16-18-017.

DOI: 10.21883/FTT.2018.10.46526.097

\section{1. Введение}

Особенностью полимерных систем из кристаллизующихся гибкоцепных полимеров, в частности полиолефинов (полиэтилен, полипропилен), является их способность к формированию надмолекулярных структур с большим разнообразием структурных элементов - типа кристаллитов, их пространственного расположения, размеров и степени связанности между собой, наличия ориентации и степени дефектности. Основные характеристики надмолекулярной структуры образцов зависят от способа ее формирования - условий кристаллизации и последующей обработки, таких как ориентационные вытяжки и термический отжиг [1-4]. Структурная организация определяет физико-механические свойства полимерных материалов и соответственно области их использования, поэтому исследование влияния параметров процесса получения на структуру и характеристики образцов представляет интерес как с фундаментальной, так и с практической точек зрения.

Возможность варьирования в широких пределах надмолекулярной структуры гибкоцепных полимеров позволяет получать из них материалы с различным сочетанием свойств и характеристик. Так, известно [3,5], что наличие дефектов в аморфно-кристаллической структуре полимера приводит к снижению прочностных характеристик образцов. В то же время разработаны способы получения из этих полимеров пористых пленок [6-10], включающие направленное инициирование дефектов пор - необходимого для выбранной цели числа и размеров при сохранении достаточного уровня механической прочности и эластичности. Наиболее перспективным методом приготовления пористых пленок из полиолефинов является процесс, основанный на экструзии расплава полимера, т.к. он является экологически безопасным (в отличие от растворных методов, где используются токсичные растворители) и технологически эффективным. В этом процессе исходная структура образца формируется при кристаллизации экструдированной пленки на воздухе после выхода из фильеры. Экструдированные образцы, состоящие из ламеллярных кристаллитов и имеющие ориентированную структуру, обусловленную фильерной вытяжкой, подвергаются отжигу в изометрических условиях (при фиксированных концах образца) для предотвращения их усадки при нагревании. Назначение отжига состоит в совершенствовании кристаллической структуры за счет вовлечения цепей из аморфной части в кристаллиты и, как результат, увеличение числа напряженных проходных цепей, способных держать нагрузку [10-14]. Такие образцы имеют так называемые жесткоэластические свойства способность к большим упругим обратимым деформациям при высоком модуле упругости. Пористая структура в этом процессе формируется при последующем одноосном растяжении жесткоэластических пленок, которое приводит к раздвижению кристаллитов и появлению между ними (вследствие „обеднения“ аморфной части) разрывов сплошности - пор. Возможность получения пористых образцов, и в частности, проницаемых пленок, 
т. е. содержащих сквозные каналы, и их характеристики зависят от структуры жесткоэластических образцов размеров кристаллитов и степени ориентации.

Целью данной работы было исследование влияния температуры отжига - основного контролирующего параметра на стадии отжига - на кристаллическую структуру жесткоэластических и пористых пленок полипропилена (ПП) и их механические свойства.

\section{2. Объекты и методы исследования}

Для получения пленок использовали гранулы изотактического полипропилена PPG 1035 (Ставролен, Россия) с молекулярной массой $M_{w}=380000$, полидисперсностью $M_{w} / M_{n}=4-5$.

Формование пленок проводили на лабораторном экструдере SCAMIA (Франция), снабженном плоскощелевой фильерой с зазором $1.5 \mathrm{~mm}$, при температуре расплава на выходе из экструзионной головки $200^{\circ} \mathrm{C}$. Кристаллизация полимера происходила на воздухе. Для исследования использовали пленки, экструдированные при кратности фильерной вытяжки (отношение скорости приема пленки к скорости ее выхода из формующей головки) $\lambda=78$.

Экструдированные пленки подвергали изометрическому отжигу (в условиях фиксации концов пленки) в течение $1 \mathrm{~h}$ при варьировании температуры отжига $\left(T_{\mathrm{ann}}\right)$ от 149 до $170^{\circ} \mathrm{C}$.

Пористые пленки получали при одноосном растяжении отожженных образцов, которое проводили со скоростью $200 \% / \mathrm{min}$ до степени деформации 200\% при комнатной температуре.

Для предотвращения усадки пленок после снятия растягивающего напряжения проводили их термическую стабилизацию выдерживанием в изометрических условиях в течение $1 \mathrm{~h}$ при температуре $130^{\circ} \mathrm{C}$.

Исследования жесткоэластических образцов методом широкоуглового рентгеновского рассеяния проводили на модернизированной установке ДРОН 2.0 („Буревестник“, Ленинград) с использованием $\mathrm{Cu} K_{\alpha}$ излучения. Съемку производили „на просвет“. Измерения методом малоуглового рентгеновского рассеяния выполняли на камере „КRATKI“ с входной щелью $60 \mu$, расходимость первичного пучка составляла $3.5 \mathrm{~min}$. Были определены степень кристалличности, большой период и угол разориентации кристаллитов.

Степень ориентации образцов характеризовали фактором ориентации $f_{c}$, который вычисляли по уравнению

$$
f_{c}=\left[3\left(\cos ^{2} \varphi\right)_{c p}-1\right] / 2,
$$

где $\varphi$ - угол между направлением ориентации и направлением молекулярных цепей в кристаллитах. Для высокоориентированных систем $\left(\cos ^{2} \varphi\right)_{c p}$ совпадает с $\cos ^{2}\left(\varphi_{c p}\right) ; \varphi_{c p}$ - определяется по полуширине кривой азимутального распределения интенсивности.
Влияние температуры отжига на характеристики кристаллической структуры (температуру плавления, степень кристалличности, энтальпию плавления) для жесткоэластических и пористых пленок исследовали методом дифференциальной сканирующей калориметрии (ДСК). Измерения производили на приборе DSC 204 F1 (NETZSCH, Германия) в инертной среде (аргон) при скорости нагревания $10^{\circ} \mathrm{C} / \mathrm{min}$. При расчете степени кристалличности использовали теплоту плавления идеального кристалла ПП (165 J/g) [15].

Механические характеристики образцов рассчитывали с помощью кривых напряжение-деформация, полученных на разрывной машине 2166 Р-5 („Точприбор“, Иваново, Россия). Прочность, модуль упругости и относительную деформацию при разрыве измеряли при одноосном растяжении образцов со скоростью $100 \% / \mathrm{min}$.

Величины обратимой деформации $E R_{100}$ для жесткоэластических пленок определяли при циклическом нагружении до степени растяжения $100 \%$ со скоростью $100 \% / \mathrm{min}$.

Скорость распространения звука измеряли с помощью прибора „Puls Propagation Meter PPM-5R“ (H.M. Morgan Comp., USA). По результатам измерений скорости распространения продольных звуковых волн с частотой $10 \mathrm{kHz}$, проходящих через пленку, были получены полярные диаграммы скорости распространения звукового импульса. При записи диаграмм направление 0-180 выбирали в направлении экструзии пленок.

Пористые пленки были охарактеризованы значениями общей пористости, проницаемости и размера пор. Общую пористость образцов $(P)$ (доля объема образца, занятая порами) рассчитывали по соотношению плотности исследуемых образцов и известной плотности непористой пленки полипропилена по формуле

$$
P=\left[\left(\rho-\rho_{n}\right) / \rho\right] \cdot 100 \%,
$$

где $\rho-$ плотность монолитной полипропиленовой пленки $\left(0.9 \mathrm{~g} / \mathrm{cm}^{3}\right), \rho_{n}-$ плотность пористой пленки рассчитывали как отношение массы пленки к ее объему: вырезали образец размерами $50 \times 90 \mathrm{~mm}$, толщину пленки измеряли цифровым микрометром „Vogel 0-50x0.001“ (Германия), массу определяли по взвешиванию.

Проницаемость пленок для жидкости $(G)$ определяли по скорости протекания смачивающей ПП жидкости (этанол) под давлением $0.5 \mathrm{MPa} \mathrm{через} \mathrm{пористый} \mathrm{образец,}$ помещенный в фильтрационную ячейку, и рассчитывали по формуле:

$$
G=V /(S \tau p K),
$$

где $V$ - объем жидкости, протекающей через пористую пленку площадью $S$ за время $\tau$ под действием давления $p, K-$ постоянная ячейки.

Распределения по размерам сквозных каналов получали методом фильтрационной порометрии при измерении потока несмачивающей жидкости (30\%-ая смесь этанол-вода) через пленку в зависимости от давления $[6,16]$. 


\section{3. Результаты и обсуждение}

\section{1. Формирование структуры жесткоэластических ПП пленок при отжиге}

В используемом процессе получения пористых пленок, включающем экструзию, отжиг, одноосное растяжение и термофиксацию $[8,17]$, надмолекулярная структура жесткоэластических образцов, сформированная на стадии отжига, определяет результат порообразования при их последующем одноосном растяжении. При отжиге экструдрованных пленок происходит трансформация их структуры, состоящей из складчатых ламелей, расположенных параллельно друг другу и перпендикулярно направлению течения расплава (направлению ориентации). Складчатые кристаллы являются метастабильной формой при кристаллизации - равновесную форму представляют кристаллы с полностью выпрямленными цепями. Однако, при кристаллизации в условиях больших переохлаждений (при комнатной температуре) равновесная форма по кинетическим причинам недоступна для гибкоцепных полимеров, молекулы которых имеют в расплаве форму свернутого клубка, поэтому они кристаллизуются в кинетически более доступной складчатой форме. При отжиге в области повышенных температур, при которых начинается движение цепей в кристаллитах, становится возможной их перестройка в направлении приближения к равновесному состоянию. Ламели, расположенные параллельно друг другу, образуют стопки, связанные между собой тяжами разной степени напряженности.

Исследование структуры жесткоэластических образцов в зависимости от температуры отжига проводили методом рентгеновского рассеяния. Как видно на рис. 1, с увеличением $T_{\text {ann }}$ трансформация структуры происходит все более эффективно вследствие возрастания подвижности цепей в кристаллитах, что приводит к росту толщины ламелей и рентгеновского большого периода (суммы толщины ламели и размера аморфной прослойки в направлении ориентации). Исследования показали, что толщина ламелей не зависит от температуры отжига вплоть до температуры $T_{\mathrm{ann}}=130^{\circ} \mathrm{C}$, что согласуется с данными динамического механического анализа, показавшими, что движение цепей в кристаллитах полипропилена начинается при температурах $130-140^{\circ} \mathrm{C}[17]$, поэтому изменения структуры наблюдаются при $T_{\text {ann }}>140^{\circ} \mathrm{C}$ (рис. 1). Согласно данным рентгеновского рассеяния, отожженные образцы имеют более высокую степень кристалличности, чем экструдированные $(51 \%)$, и в области $T_{\text {ann }}$ от 150 до $170^{\circ} \mathrm{C}$ eе величина возрастает от 56 до $62 \%$.

Поскольку отжиг проводили при закрепленных концах образца, т.е. образец при кристаллизации находился под напряжением, то процесс перестройки структуры сопровождается повышением степени ориентации, которую характеризовали фактором ориентации $f_{c}$. Рис. 1

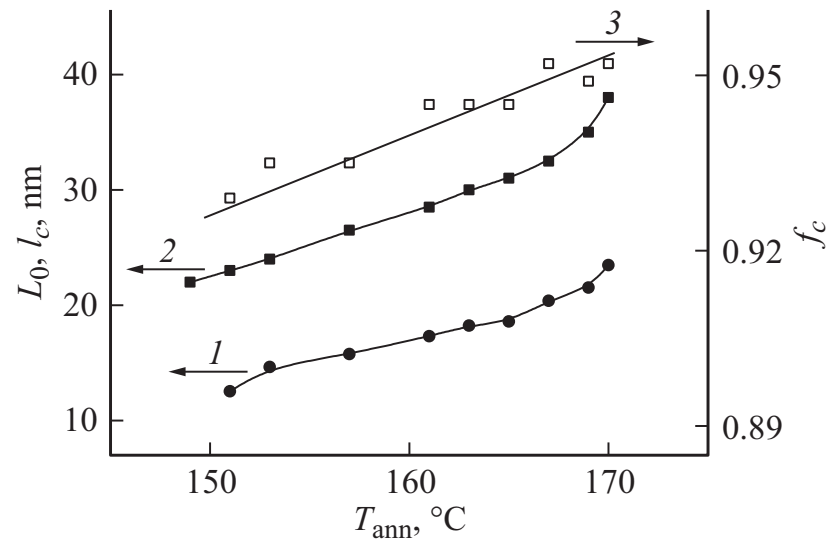

Рис. 1. Изменение характеристик структуры жесткоэластических образцов (рентгеновского большого периода $L_{0}(1)$, толщины ламелей $l_{c}(2)$ и фактора ориентации $\left.f_{c}(3)\right)$ с температурой отжига.

показывает, что чем выше температура отжига, тем более высокоориентированная структура формируется в жесткоэластических образцах - значение $f_{c}$ повышается от 0.87 для экструдированных пленок до 0.95 для отожженных.

Данные ДСК иллюстрируют изменения кристаллической структуры жесткоэластических пленок при варьировании температуры отжига (табл. 1). Видно, что увеличение толщины ламелей сопровождается ростом температуры и энтальпии плавления. Отметим, что результаты по возрастанию степени кристалличности находятся в хорошем согласии с приведенными выше рентгеновскими данными.

Жесткоэластические свойства отожженных пленок характеризуются основными показателями - величиной обратимой деформации $\left(E R_{100}\right)$ и модулем упругости при растяжении. Для гибкоцепных полимеров область упругих деформаций, как правило, не превышает 5-10\%. Исходные экструдированные ПП пленки, будучи ориентированными, имели $E R_{100}=48 \%$. Как видно в табл. 2, $E R_{100}$ для отожженных пленок увеличивается с $T_{\text {ann }}$ от 81 до $87 \%$, т. е. все образцы демонстрируют очень высокую способность к упругим деформациям. В табл. 2 представлены также механические характеристики пленок при растяжении в зависимости от $T_{\text {ann }}$ в направлении ориентации и в перпендикулярном направлении. Данные показывают, что с ростом $T_{\text {ann }}$ в направлении ориентации возрастает модуль упругости, который достигает значений $2300 \mathrm{MPa}$, и снижается удлинение при разрыве, что объясняется ростом напряжения в образце вследствие усиления тенденции к усадке при повышении $T_{\text {ann }}$ и свидетельствует о повышении жесткоэластичности пленок. Как было установлено в [11], формирование такой структуры, обладающей сочетанием высоких значений модуля упругости и способности к большим упругим обратимым деформациям, является необходимым условием для появления пор на стадии одноосного растяжения жесткоэластических пленок. 
Таблица 1. Данные ДСК для жесткоэластических образцов полипропилена

\begin{tabular}{c|c|c|c}
\hline $\begin{array}{c}\text { Температура } \\
\text { отжига, }{ }^{\circ} \mathrm{C}\end{array}$ & $\begin{array}{c}\text { Температура } \\
\text { плавления, }{ }^{\circ} \mathrm{C}\end{array}$ & $\begin{array}{c}\text { Энтальпия } \\
\text { плавления, } \mathrm{J} / \mathrm{g}\end{array}$ & $\begin{array}{c}\text { Степень } \\
\text { кристалличности, \% }\end{array}$ \\
\hline 149 & 165.8 & 97.5 & 69 \\
155 & 166.4 & 98.2 & 62 \\
161 & 168.0 & 101.4 & 63 \\
170 & 169.1 & 103.4 & 64
\end{tabular}

Таблица 2. Механические свойства жесткоэластических ПП пленок*

\begin{tabular}{c|c|c|c|c}
\hline $\begin{array}{c}\text { Температура } \\
\text { отжига, }{ }^{\circ} \mathrm{C}\end{array}$ & $\begin{array}{c}\text { Обратимая } \\
\text { деформация, } E R_{100}, \%\end{array}$ & $\begin{array}{c}\text { Прочность, } \\
\text { МРа }\end{array}$ & $\begin{array}{c}\text { Модуль } \\
\text { упругости, МРа }\end{array}$ & $\begin{array}{c}\text { Удлинение } \\
\text { при разрыве, \% }\end{array}$ \\
\hline 149 & 81 & $81 / 27$ & $1600 / 1450$ & $400 / 2.5$ \\
155 & 82 & $80 / 28$ & $1800 / 1480$ & $360 / 2.5$ \\
161 & 83 & $80 / 28$ & $2000 / 1520$ & $320 / 2.5$ \\
165 & 85 & $79 / 29$ & $2100 / 1540$ & $300 / 2.5$ \\
170 & 87 & $79 / 29$ & $2300 / 1570$ & $270 / 2.5$
\end{tabular}

Примечани е. * В числителе приведены значения характеристик в направлении ориентации, в знаменателе - в перпендикулярном.

Таблица 3. Данные ДСК для пористых пленок полипропилена

\begin{tabular}{c|c|c|c}
\hline $\begin{array}{c}\text { Температура } \\
\text { отжига, }{ }^{\circ} \mathrm{C}\end{array}$ & $\begin{array}{c}\text { Температура } \\
\text { плавления, }{ }^{\circ} \mathrm{C}\end{array}$ & $\begin{array}{c}\text { Энтальпия } \\
\text { плавления, } \mathrm{J} / \mathrm{g}\end{array}$ & $\begin{array}{c}\text { Степень } \\
\text { кристалличности, \% }\end{array}$ \\
\hline 149 & 163.3 & 86.3 & 52 \\
155 & 165.1 & 89.4 & 54 \\
161 & 166.2 & 95.0 & 59 \\
165 & 167.1 & 97.8 & 60
\end{tabular}

Различие значений механических характеристик жесткоэластических пленок в направлении ориентации (\|) и в перпендикулярном направлении $(\perp)$ есть результат ориентированного характера их надмолекулярной структуры. Рост соотношения модулей упругости $E_{\|} / E_{\perp}$

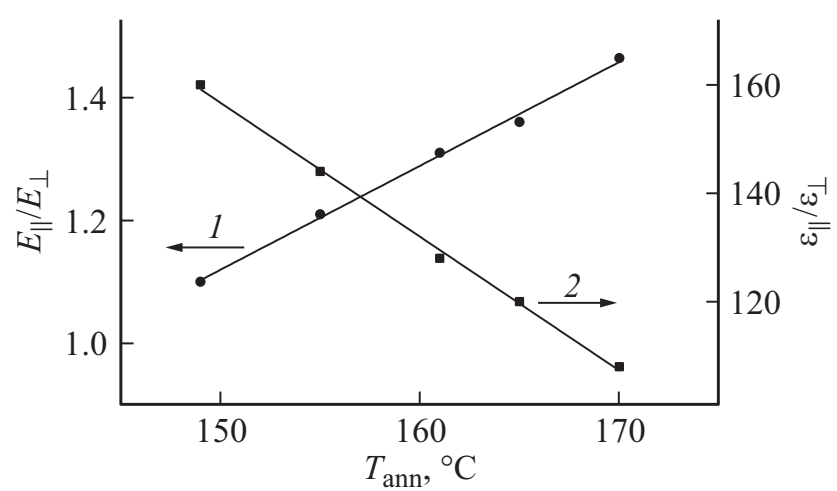

Рис. 2. Соотношения значений модуля упругости (1) и разрывного удлинения (2) в направлении ориентации и в перпендикулярном направлении для жесткоэластических образцов в зависимости от температуры отжига. (рис. 2) свидетельствует о повышении анизотропии механических свойств как следствия увеличения степени ориентации пленок с ростом $T_{\text {ann. }}$ В то же время отношение $\varepsilon_{\|} / \varepsilon_{\perp}$ с ростом $T_{\text {ann }}$ снижается из-за снижения $\varepsilon_{\|}$при неизменном $\varepsilon_{\perp}$, что можно объяснить тем, что фиксирующее усилие приложено к образцу в направлении ориентации, и перестройка структуры происходит главным образом в этом направлении, не оказывая заметного влияния на поперечные связи между кристаллитами.

\section{2. Влияние температуры отжига на структуру пористых пленок}

Как было показано в работах [10-12], растяжение жесткоэластических образцов в силу особенностей их структуры происходит не по энтропийному механизму, типичному для аморфно-кристаллических полимеров, при котором напряжение приложено к цепям в аморфной части, а по механизму, типичному для деформации твердых тел. Нагрузку в этом случае принимают на себя кристаллические ламели, соединенные жесткими „мостиками“ (тяжами). Деформация такой структуры 


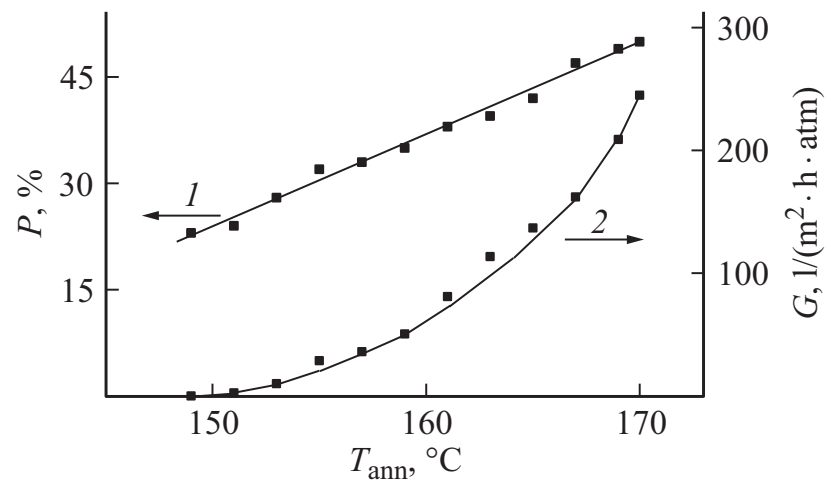

Рис. 3. Зависимости общей пористости $P(1)$ и проницаемости $G(2)$ пористых пленок от температуры отжига.

приводит к раздвижению и изгибу ламелей между точками, соединенными тяжами, разрыву некоторой части тяжей и появлению пор. Понятно, что свойства получаемых пористых пленок зависят от характеристик жесткоэластических образцов, которые, как показано выше, регулируются температурой отжига. Изменение структуры этих образцов с ростом $T_{\text {ann }}$ приводит в пористых пленках к увеличению числа и размеров пор и, как следствие, их слиянию и образованию сквозных каналов - пленка становится проницаемой для протекания жидкости. На рис. 3 представлены зависимости общей пористости и проницаемости ПП пленок от $T_{\text {ann }}$. Как видно на рисунке, общая пористость увеличивается с $T_{\text {ann }}$ во всем интервале ее варьирования; в то же время проницаемость (сквозные каналы) появляются только тогда, когда температура отжига при получении жесткоэластических образцов была выше $149^{\circ} \mathrm{C}$ - температуры, при которой достигается пороговое для перколяционного параметра - пористости, составляющего для ПП пленок 23\% [17,18,19]. Дальнейшее повышение $T_{\text {ann }}$ приводит к росту проницаемости пористых пленок. На рис. 4 видно, что в увеличение проницаемости вносит вклад возрастание как числа, так и размеров сквозных пор.

Данные ДСК (табл. 3) показывают, что с увеличением температуры отжига увеличиваются степень кристалличности, температура и энтальпия плавления пористых пленок, т.е. они изменяются симбатно с изменением этих характеристик для жесткоэластических образцов, однако по величине их значения несколько ниже. Это можно объяснить тем, что деформация ламелей в процессе растяжения отожженных пленок сопровождается расколом небольшого количества кристаллитов, их поворотом и перестройкой с разворачиванием в тяжи. Об этом свидетельствует и небольшое снижение фактора ориентации $f_{c}$ от 0.95 до 0.93 для отожженных и пористых образцов соответственно.

На рис. 5 представлены результаты измерения скорости распространения звука для отожженного и пористого образцов $(v)$ в зависимости от направления его распространения. Более высокая скорость распростра- нения звука в пористом образце, чем в отожженном (1.75 и $1.20 \mathrm{~km} / \mathrm{s}$ соответственно), а также соотношение между скоростями в направлении ориентации и в поперечном направлении $\left(v_{\|} / v_{\perp}=1.5\right.$ и 1.3 соответственно), свидетельствует об увеличении числа напряженных кристаллических тяжей в пористой пленке при одноосном растяжении.

Измерения механических характеристик пористых пленок показали, что их прочность и модуль упругости закономерно снижаются в соответствии с увеличением числа и размера пор при повышении $T_{\text {ann. Деформация }}$ и изгиб ламелей при растяжении приводит к снижению модуля упругости пористых пленок по сравнению с жесткоэластическими образцами как в направлении ориентации, так и в перпендикулярном направлении,

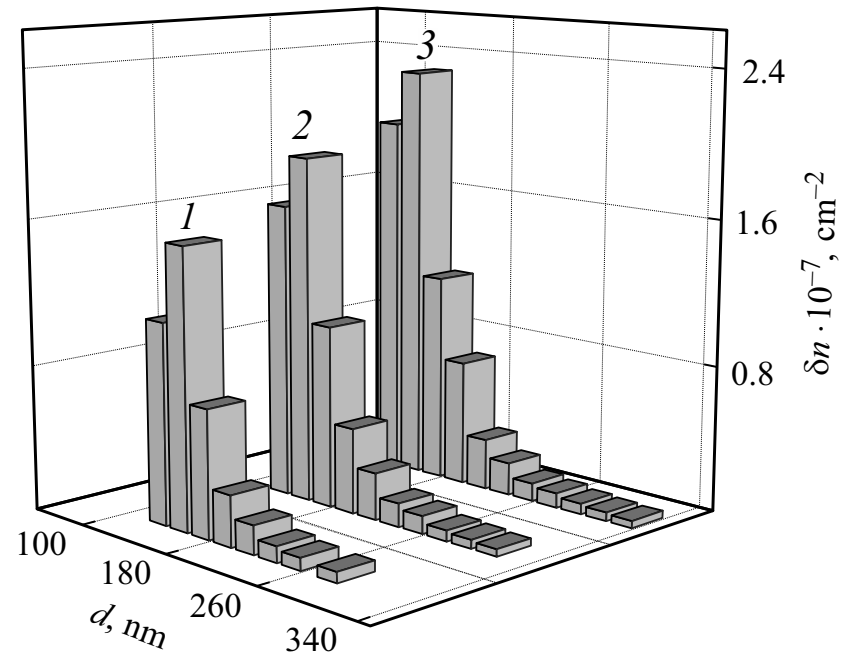

Рис. 4. Распределения по размерам сквозных каналов для пористых ПП пленок, полученных при различных температурах отжига $170(3), 167$ (2) и $163^{\circ} \mathrm{C}(1) . d$ - диаметр пор; $\delta n-$ число сквозных пор в интервале размеров от $d_{i}$ до $d_{i+1}$.

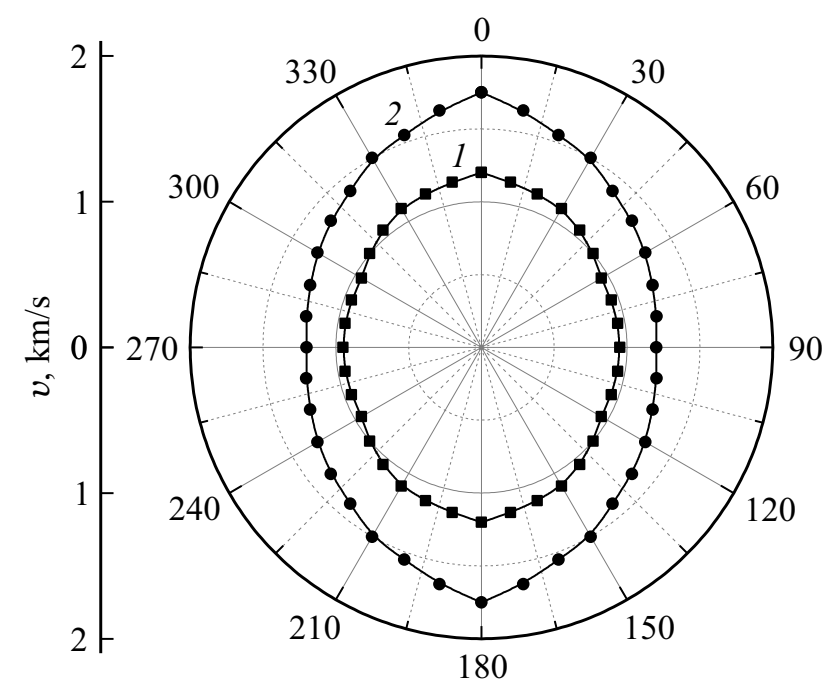

Рис. 5. Скорость распространения звука в плотных (1) и пористых (2) ПП пленках. 
Таблица 4. Механические свойства жесткоэластических ПП пленок*

\begin{tabular}{c|c|c|c}
\hline $\begin{array}{c}\text { Температура } \\
\text { отжига, }{ }^{\circ} \mathrm{C}\end{array}$ & $\begin{array}{c}\text { Прочность, } \\
\text { МРа }\end{array}$ & $\begin{array}{c}\text { Модуль } \\
\text { упругости, МРа }\end{array}$ & $\begin{array}{c}\text { Удлинение } \\
\text { при разрыве, \% }\end{array}$ \\
\hline 149 & $189 / 11.3$ & $1400 / 700$ & $47 / 100$ \\
155 & $166 / 11.0$ & $1200 / 620$ & $47 / 140$ \\
161 & $143 / 10.8$ & $1000 / 550$ & $47 / 160$ \\
165 & $130 / 10.5$ & $850 / 470$ & $47 / 180$ \\
170 & $110 / 10.3$ & $700 / 400$ & $47 / 200$
\end{tabular}

Примечание. * В числителе приведены значения характеристик в направлении ориентации, в знаменателе - в перпендикулярном.

тем более заметному, чем выше $T_{\text {ann }}$ (табл. 4). Однако, пористые пленки характеризуются более высоким соотношением между модулями упругости в этих направлениях, что свидетельствует об увеличении анизотропии механических свойств в результате растяжения. В то же время прочность пористых пленок, несмотря на появление дефектов в виде пор, в направлении ориентации значительно выше, чем отожженных, что связано с повышением числа держащих нагрузку цепей в аморфной области под влиянием ориентирующих воздействий в процессе растяжения жесткоэластических пленок. Однако, эти значения прочности снижаются с $T_{\text {ann }}$ в результате увеличения размера пор и разрыва части напряженных тяжей, соединяющих ламели. Эти изменения структуры проявляются и в значительном снижении (в 5-6 раз) удлинения при разрыве в направлении ориентации (табл. 2 и 4).

На деформируемость пленок в направлении, перпендикулярном ориентации, появление пор также оказывает существенное влияние, свидетельствующее о нарушении связей между стопками ламелей при растяжении в результате их смещения относительно друг друга. Так, прочность в этом направлении у пористых пленок в 2.5 раза ниже, чем у отожженных. Это влияние проявляется и в увеличении разрывного удлинения, причем

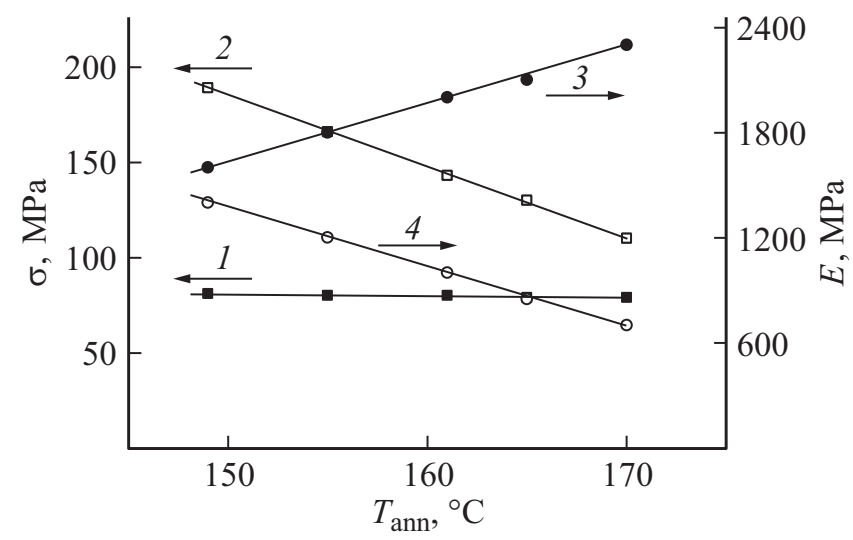

Рис. 6. Влияние температуры отжига на прочность $(1,2)$ и модуль упругости $(3,4)$ отожженных $(1,3)$ и пористых $(2,4)$ пленок полипропилена. деформация пористых пленок в перпендикулярном направлении проходила по механизму шейкообразования, что дало резкое повышение измеренных величин $\varepsilon_{\perp}$, возрастающих от 100 до $200 \%$ с ростом $T_{\text {ann }}$ по сравнению с $\varepsilon_{\perp}$ для отожженных образцов, которое составляло $2.5 \%$ независимо от $T_{\text {ann }}$ (табл. 2).

Приведенные результаты позволяют сделать следующие выводы о влиянии температуры отжига в интервале от 150 до $170^{\circ} \mathrm{C}$ на структуру и свойства жесткоэластических и пористых пленок полипропилена (рис. 6):

- для жесткоэластических образцов повышение $T_{\mathrm{ann}}$ приводит к увеличению толщины и степени ориентации кристаллических ламелей, что проявляется в возрастании модуля упругости и соответствующем снижении разрывного удлинения, но вызывает снижение прочности в результате сокращения числа проходных цепей, которые входят в кристаллиты, обеспечивая увеличение их размера;

- для пористых пленок при повышении $T_{\text {ann }}$ увеличивается пористость и проницаемость, но снижается прочность и модуль упругости в результате снижения ориентации при раздвижении и изгибе ламелей в процессе образования пор. Однако, прочность пористых пленок значительно выше, чем отожженных, вследствие роста числа держащих нагрузку цепей под действием растяжения жесткоэластических образцов в направлении ориентации.

\section{4. Заключение}

Проведенные исследования влияния отжига на структуру и характеристики жесткоэластических и полученных их растяжением пористых пленок полипропилена показали, что температура отжига является определяющим параметром процесса формирования пористой структуры с точки зрения как функциональных (пористость, проницаемость, размер пор), так и механических свойств данных пористых материалов. Они позволили установить механизм трансформации структуры при отжиге и выявить зависимость характеристик пористых пленок от условий термической обработки жесткоэластических образцов. Результаты исследований приводят к выводу, что для формирования высокопроницаемых пленок необходимо проводить отжиг жесткоэластических образцов при температурах, близких к температуре плавления полимера, и показывают, что при этом пористые пленки имеют высокую прочность и сохраняют механическую целостность, а именно, не подвержены фибриллизации при нагружении в обоих направлениях. Полученные пористые ПП пленки обладают высокой пористостью и сквозной проницаемостью, которые достигают $50 \%$ и $245 \mathrm{l} /\left(\mathrm{m}^{2} \cdot \mathrm{h} \cdot \mathrm{atm}\right)$, соответственно, в сочетании с механической прочностью при малой толщине $(\sim 17 \mu)$, что позволяет рассматривать их как перспективные мембранно-сепарационные материалы, характеризующиеся низким сопротивлением массопереносу. 


\section{Список литературы}

[1] Л. Манделькерн. Кристаллизация полимеров. Химия, М.Л. (1966). 336 с.

[2] Ф.Х. Джейл. Полимерные монокристаллы. Химия, Л. (1968). $552 \mathrm{c}$.

[3] В.А. Марихин, Л.П. Мясникова. Надмолекулярная структура полимеров. Химия, Л. (1977). 240 с.

[4] С.Я. Френкель, Г.К. Ельяшевич. В кн.: Ориентационные явления в растворах и расплавах полимеров. Химия, М. (1980). C. 9-90.

[5] V.A. Marikhin, L.P. Myasnikova. In: Oriented Polymer Materials / Ed. S. Fakirov. Huthig \& Wepf Verlag Zug. Heidelberg, Germany (1996). 512 p.

[6] R.E. Kesting. Synthetic polymer membranes. A structural perspective. 2nd. John Wiley \& Sons, N.Y.-Chichester (1985). 348 p.

[7] M. Mulder. Basic Principles of Membrane Technology. Kluwer Acad. Publ., Dordrecht. (1991). 363 p.

[8] Г.К. Ельяшевич, Е.Ю. Розова, Е.А. Карпов. Патент РФ № 2140936. (1997).

[9] А.Л. Волынский, А.Ю. Ярышева, Е.Г. Рухля, Л.М. Ярышева, Н.Ф. Бакеев. Докл. РАН 454, 56 (2014).

[10] Е.А. Карпов, В.К. Лаврентьев, Е.Ю. Розова, Г.К. Ельяшевич. Высокомолекулярн. соединения 37 А, 2035 (1995).

[11] I.K. Park, H.D. Noether. Colloid Polym. Sci. 253, 824 (1975).

[12] B.S. Spague. J. Macromol. Sci. Phys. 8, 157 (1973).

[13] Г.К. Ельяшевич, Е.Ю. Розова, Е.А. Карпов. Высокомолекулярн. соединения 33 Б, 723 (1991).

[14] S. Hild, W. Gutmannsbauer, R. Luthi, J. Fuhrmann, H.-J. Guntherotd. J. Polym. Sci. Polym. Phys. 34, 1953 (1996).

[15] B. Wunderlich. Macromolecular Physics. Crystal Melting. Academic Press, N.Y. (1980). V. 3. 363 p.

[16] Г.К. Ельяшевич, А.Г. Козлов, Е.Ю. Розова. Высокомолекулярн. соединения 40 А, 956 (1998).

[17] Г.К. Ельяшевич, И.С. Курындин, В.К. Лаврентьев, А.Ю. Бобровский, V. Bukošek. ФТТ 54, 1787 (2012).

[18] И.С. Курындин, В.К. Лаврентьев, V. Bukošek, Г.К. Ельяшевич. Высокомолекулярн. соединения 57 А, 497 (2015).

[19] G.K. Elyashevich. D.V. Novikov, I.S. Kuryndin, A. Jelen, V. Bukošek. Acta Chim. Slovenica 64, 980 (2017).

Редактор Т.Н. Василевская 